\title{
Classification, structure and molecular diagnostics of avian hepatitis E virus
}

\author{
JOANNA NERC, PIOTR SZELESZCZUK
}

\begin{abstract}
Department of Pathology and Veterinary Diagnostics, Division of Avian Diseases, Faculty of Veterinary Medicine, Warsaw University of Life Sciences - SGGW, Nowoursynowska 159, 02-776 Warsaw, Poland
\end{abstract}

\section{Nerc J., Szeleszczuk P.}

\section{Classification, structure and molecular diagnostics of avian hepatitis E virus}

\section{Summary}

Pathological syndromes caused by avian hepatitis $\mathrm{E}$ virus have been described as big liver and spleen disease; necrotic haemorrhagic hepatitis-splenomegaly syndrome; necrotic, haemorrhagic, hepatomegalic hepatitis; or hepatitis-liver haemorrhage syndrome. The aetiological factor of this syndrome belongs to the Hepeviridae family. Avian hepatitis E virus is a single-strand RNA virus whose genome consists of approx. 7,200 base pairs and contains a short non-coding 5 ' terminus (27-35 nucleotides) followed by three partially overlapping open reading frames: ORF1, ORF3 and ORF2. Since the avian strains of hepatitis viruses do not replicate in cell cultures, molecular biology techniques are used in the diagnosis of infections. This article discusses in detail the structure and function of each ORF of avian hepatitis $\mathbf{E}$ virus, as well as methods for the identification of the genetic material of this pathogen.

Keywords: avian hepatitis E virus taxonomy, structure, molecular diagnostics

Pathological syndromes caused by avian hepatitis E virus (aHEV) have been described under different names, depending on the country in which they were observed. The most commonly used terms are big liver and spleen disease (BLS), hepatitis-splenomegaly syndrome (HSS) (1), necrotic, haemorrhagic, hepatomegalic hepatitis, or hepatitis-liver haemorrhage syndrome $(1,6,8,11,22)$. In Poland, the first description of a clinical case of BLS was presented in 2011 at the 1st Veterinary Practice Congress in Łódź (31), although field practitioners had already been observing this syndrome for a few years, at least from 2007 (33).

\section{Taxonomy}

Hepatitis E virus (HEV) was initially assigned to the Caliciviridae family, but this was later changed when it became apparent that HEV and caliciviruses differ in many aspects (3).

It was proposed that a new taxonomic unit named Hearviridae (hepatitis $\mathrm{E}$ and related viruses) be created that would consisted of hepatitis E virus and HEV-like viruses (9). Finally, in 2004, HEV was classified as a member of the Hepeviridae family (11).

Since then, the taxonomy of this family has been changed several times as new data emerged. Initially, it was proposed that the Hepevirus genus be replaced by two separate genera: Orthohepevirus and Avihepevirus $(20,21)$. In light of newly isolated virus strains, another change in taxonomy was necessary, and in 2014 the current taxonomic structure was established (Tab. 1). According to this classification, the Hepeviridae family is divided into two genera: Orthohepevirus and Piscihepevirus. Avian hepatitis E virus belongs to the Orthohepevirus genus and the Orthohepevirus B species (26). Emerging new research results suggest that the taxonomy of these pathogens will undergo modifications. Among these new data, new virus strains not yet assigned to any group were discovered in wild birds in 2015 and 2016. The virus strain occurring in the little egret (Egretta garzetta garzetta) had the most similar structure to that of avian strains occurring mainly in poultry, while strains occurring in birds of prey, such as the common kestrel (Falco tinnunculus) and the red-footed falcon (Falco vespertinus), had a structure similar to that of the Orthohepevirus $C$ species (occurring in rats and ferrets), which may be associated with the diet of these birds (preying on voles, shrews and mice), and of the Orthohepevirus A species, genotype 4 (occurring in humans and pigs) $(24,25)$. On the other hand, a strain detected in the Himalayan vultures (Gyps himalayensis) kept in the Beijing Zoo demonstrated the highest similarity to Orthohepevirus A, genotype 3, 
Tab. 1. Taxonomy of the Hepeviridae family according to Smith et al. (2014), including the aHEV genotypes proposed by Billic et al. (2009) and the recently described, but not yet assigned, species (16, $17,24,25,37,38)$

\begin{tabular}{|c|c|c|c|c|}
\hline Family & Genus & Species & Main host species & Genotype \\
\hline \multirow{20}{*}{ 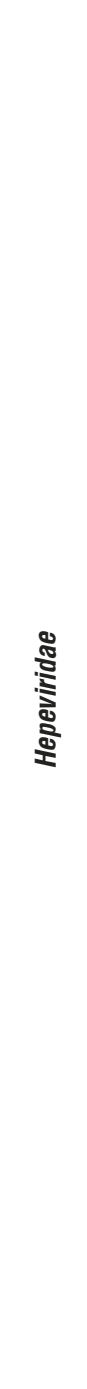 } & \multirow{19}{*}{ 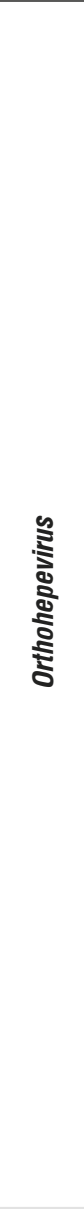 } & \multirow{7}{*}{ Orthohepevirus A } & Human & HEV - 1 \\
\hline & & & Human & HEV - 2 \\
\hline & & & $\begin{array}{l}\text { Human, pig, rabbit, } \\
\text { deer, mongoose }\end{array}$ & HEV - 3 \\
\hline & & & Human, pig & HEV - 4 \\
\hline & & & Boar & HEV - 5 \\
\hline & & & Boar & HEV - 6 \\
\hline & & & Camel & HEV - 7 \\
\hline & & \multirow[t]{5}{*}{ Orthohepevirus B } & \multirow{5}{*}{$\begin{array}{l}\text { Hen (aHEV) } \\
\text { also detected in: } \\
\text { song thrush (Turdus } \\
\text { philomelos), little owl } \\
\text { (Athene noctua), feral } \\
\text { pigeon (Columba livia } \\
\text { domestica), common } \\
\text { buzzard (Buteo buteo) }\end{array}$} & $\begin{array}{l}\text { Genotype } 1 \\
\text { Australian (AaHEV) }\end{array}$ \\
\hline & & & & $\begin{array}{l}\text { Genotype } 2 \\
\text { USA (USAaHEV) } \\
\text { - pUSAaHEV } \\
\text { - aavUSAaHEV }\end{array}$ \\
\hline & & & & $\begin{array}{l}\text { Genotype } 3 \\
\text { European (EaHEV) } \\
\text { China (CaHEV) }\end{array}$ \\
\hline & & & & Genotype 4 (?) \\
\hline & & & & Genotype 5 (?) \\
\hline & & \multirow[t]{2}{*}{ Orthohepevirus C } & Rat & HEV - C1 \\
\hline & & & Ferret & HEV - C2 \\
\hline & & Orthohepevirus D & Bat & \\
\hline & & Unassigned & Himalayan vulture & \\
\hline & & Unassigned & Common kestrel & \\
\hline & & Unassigned & Red-footed falcon & \\
\hline & & Unassigned & Little egret & \\
\hline & 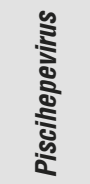 & Piscihepevirus A & Trout & \\
\hline
\end{tabular}

which is present in humans and pigs, as well as in such species as rabbit, deer and mongoose. In this case, interspecific infection was suspected, but virus multiplication in the body of birds was not confirmed (16).

It is assumed that the first clinical case of infectious hepatitis $\mathrm{E}$ in a human occurred as early as in 1794 in Germany, but the aetiological factor causing this disease had not been determined as HEV until 1991 (1). Before the first cases of the disease were observed in pigs (1997), the disease had been presumed to be transmitted only between humans (14).
Since 2010, mainly thanks to novel diagnostic methods, more pathogens similar to hepatitis E virus have been discovered in rats, rabbits, ferrets, mink, foxes, bats, mice and salmonids (14).

To date, four or five genotypes of hepatitis $E$ virus, depending on the source, have been identified. According to Huang et al. (12), the entire HEV group was divided into five genotypes, among which the genotype 5 group included isolates of avian hepatitis E virus. Subsequent publications suggested only four main genotypes, including genotypes of human and swine viruses (1). Genotypes 1 and 2 were strictly assigned to human viruses, while genotypes 3 and 4 were genotypes of viruses infecting humans, as well as pigs and other animals $(19,20,23)$. In 2010, Meng (20) distinguished separate strains of poultry hepatitis E virus, but did not specifically assign them to genotype 5 (Fig. 1). Currently, it is believed that distinguishing the avian genotype, along with the human and swine genotypes, was inappropriate. Within the Orthohepevirus A genus, 7 genotypes are currently distinguished. Apart from the previously identified first four genotypes, novel genotypes 5 and 6 from wild boars and genotype 7 from camels have been isolated (35), while the genotypes of viruses isolated from birds have been grouped in the separate Orthohepevirus $B$ genus (26).

In 2009, a division of aHEV into three different genotype groups was proposed: genotype 1 (Australian, AaHEV), genotype 2 (USA, USAaHEV) and genotype 3 (European, EaHEV). Moreover, genotype 2 was divided into two subgroups: pUSAaHEV and aavUSAaHEV. It was found that genotype 2, USAaHEV, is structurally most similar to hHEV (human hepatitis E virus) and sHEV (swine hepatitis E virus) $(4,27)$. Subsequent publications indicated that the aHEV group may be more complex, as the existence of genotypes 4

HEV RNA (7,200 base pair)

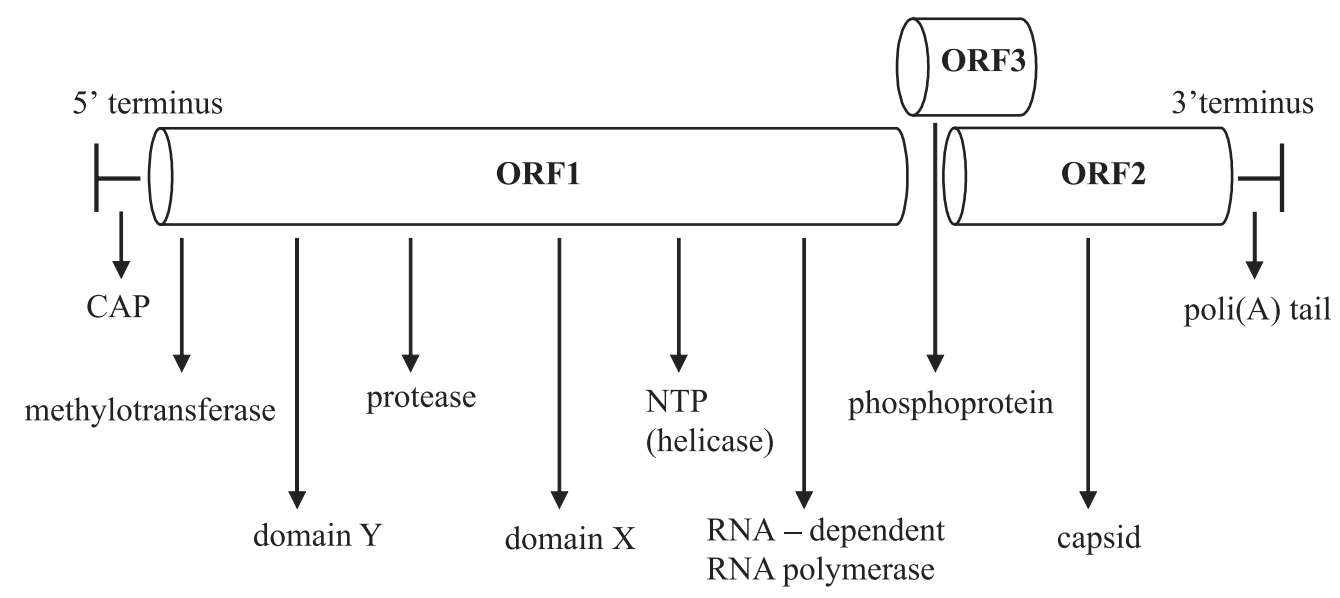

Fig. 1. Schematic diagram of the HEV genome structure 
and 5 was suggested. Currently, the Australian genotype 1 also includes isolates originating from Korea (15), the European genotype 3 also includes isolates from China (CaHEV) $(30,38)$, and it is presumed that the proposed genotype 4 consists of isolates originating from Hungary and Taiwan $(8,10)$. The proposed genotype 5 would consist of isolates from Great Britain (18). The aHEV taxonomy is additionally complicated by observations indicating differences in the structure of isolates from Russia that, for geographical reasons, were suspected to belong to the European genotype 3, but it became apparent that they did not match the structure of any of the previously described genotypes, although they were closest to the isolates originating from China $(13,27)$.

On the other hand, recent reports raised doubt about the appropriateness of the classification within the Orthohepevirus $B$ genus, as the highlighted genotypes are not very far apart from each other in terms of the genome structure. According to Smith et al. (26), the validity of the classification will be confirmed when more complete aHEV genomes are available.

In light of the currently available data, there is no doubt that avian hepatitis $\mathrm{E}$ virus and big liver and spleen virus (BLSV) are different strains of the same pathogen (23).

\section{Structure of the virus}

Avian hepatitis E virus is a single-strand RNA virus of $27 / 28-34 / 35 \mathrm{~nm}$ in size $(2,14)$, with positive-sense $(+)$ ssRNA, whose genome consists of approx. 7,200 base pairs (4). It contains a short non-coding 5' terminus (27-35 nucleotides) followed by three partially overlapping open reading frames: ORF1, ORF3 and ORF2. The non-coding 3 ' terminus (65-74 nucleotides) has a poly(A) tail of 150-200 nucleotides (34).

The structure of the HEV genome in animal and human strains is comparable. Analysis of the avian HEV genomic sequence revealed a 50-60\% similarity of the nucleotide sequence with human and swine HEVs (7).

The lack of protein envelope (as in the case of hepatitis A virus) allows the virus to be transmitted orally.

Open reading frame 1 (ORF1). ORF1 starts at the 5 ' terminus immediately after a short non-coding region consisting of 27 to 35 nucleotides. This fragment of the genome contains approx. 4,600 nucleotides [between 4,592 in the EF206691 genome (7) and 4,598 in the AM943646 (4) and GU954430 (40) genomes] and encodes a non-structural protein (polyprotein) of approximately 1,693 amino acids. The ORF1 polyprotein participates in the replication of virus particles and structural changes in proteins. From the N'terminus to the C' terminus, the following proteins can be observed: methyltransferase (MeT), domain $\mathrm{Y}$ of unknown role (similar to rubella virus and beet necrotic yellow vein virus - BNYVV), protease similar to papain (found in alphaviruses and rubella virus), domain $X$ of unknown role (similar to rubella virus, BNYVV, alphaviruses and some coronaviruses), a NTP-binding sequence associated with helicase activity (supports RNA unwinding required for replication and transcription) and RNAdependent RNA polymerase (RdRP) $(2,34)$.

Open reading frame 2 (ORF2). The ORF2 segment, according to the data available from GenBank (NC_023425, AY535004, EF206691, AM943646, AM943647 and GU954430), consists of 1,820 nucleotides followed by a 65 nucleotide long polyadenylated terminal sequence at the 3 ' terminus of the ribonucleic chain. This ORF encodes the main, if not the only capsid protein. It is a glycoprotein of approximately 71-88 $\mathrm{kDa}$ (660 amino acids, with the saccharide component at the $\mathrm{N}$ terminus) containing a potential signal region (with a high concentration of arginine and lysine) for endoplasmatic reticulum. The protein is produced as a precursor which, guided by the signal sequence, is subsequently converted into a mature protein and undergoes glycosylation at three possible sites. The presence of additional saccharides is more frequent in the superficial proteins of enveloped viruses than in the capsid proteins of non-enveloped viruses (34). The knowledge of the immune properties and structure of the ORF2 proteins is very important for the production of vaccines, since the first vaccine for humans is based on HEV-neutralizing antibodies that bind capsid proteins (36). In 2017, Syed et al. (30) showed that the truncated ORF2 protein (ORF2-C) of recombinant Chinese avian hepatitis E virus can provide complete immunoprotection against $\mathrm{CaHEV}$ infection in chickens, whereas ORF3 protein generates only partial protection.

Open reading frame $3(\mathrm{ORF} 3)$. The smallest open reading frame, ORF3, consisting of 263 nucleotides (GenBank: NC_023425, AY535004, EF206691, AM943646, AM943647 and GU954430), is located after ORF1 and overlaps 210 nucleotides (GenBank: NC_023425, AY535004, EF206691, AM943646, AM943647 and GU954430) of ORF2. It is not known precisely whether the protein encoded by ORF3 is part of the virus particle or whether it is a non-structural protein. This protein is not glycosylated, but it is phosphorylated (34). It promotes the survival and proliferation of cells. Moreover, ORF3 suppresses non-specific host response by inhibiting acute-phase reaction and promoting the secretion of immunosuppressive factors, such as alpha-1-microglobulin (2).

The size and location of each ORF slightly differ depending on the host species from which the isolate originates. Previously, a schematic diagram of the Orthohepevirus genome was presented, taking into account the known size for aHEV, i.e. Orthohepevirus $B$. Interestingly, an additional open reading frame ORF4 has been detected in the genomes of viruses isolated from certain species, with the currently confirmed pres- 
ence in rats and ferrets, isolates from which belong to the Orthohepevirus $C$ species (14).

\section{Molecular diagnostics}

Avian HEV strains do not replicate in cell cultures. In general, there is currently no effective cell culture technique for HEV isolated from animals. According to the method of Sun et al. (29), for the isolation of aHEV, SPF chickens can be used. The presence of the pathogen should be confirmed by serological or molecular methods. In order to detect the virus in samples, polymerase chain reaction (PCR), or more specifically reverse transcriptionPCR (RT-PCR), are used. aHEV RNA has been detected in bile samples and liver fragments, which confirms that the virus replicates in the liver (5).

RT-PCR is the best method of identifying avian HEV infections, but it is not known how specific it is in the detection of chicken infections in different geographical areas $(11,28)$. Nonetheless, Marek et al. (18) presented a paper describing a pair of primers that detected aHEV in cases originating from both Europe and Australia.

The literature presents a large variety of primers used for molecular diagnosis of avian hepatitis $E$ virus infections in birds, which is due to the high diversity of genotypes and variability of the virus. To detect such infections, apart from the classical RT-PCR method, nested RT-PCR and real-time RT-PCR are used. Table 2 lists primers used for aHEV diagnosis arranged in chronological order. Primer pairs 1, 2, 3 and 8 are used in molecular diagnostics employing RT-PCR, primer pairs 4, 5, 6 and 7 are used in nested RT-PCR, whereas primer pairs 9 and 10 are used in real-time RT-PCR, but primers designed by Troxler et al. (32) use a molecular probe, while primers designed by Zhao et al. (39) use SYBR Green dye. The primers can also be distinguished according to the part of the genome they detect: primer pairs 2, 3 and 4 detect helicase located within ORF1; primer pairs 6 and 7 detect another genomic fragment, also within ORF1; primer pairs 5 and 8 detect capsid, i.e. ORF2; whereas primer pairs 9 and 10 detect ORF3. The primers were designed at different times and based on different genotypes that occurred in a given area. Therefore, primer pair 1 was designed for and detected strains from Australia, whereas primer pairs 8 and 9 were designed for and detected strains patitis $\mathbf{E}$ virus
Tab. 2. Summary of primers used to detect the genetic material of avian he-

\begin{tabular}{|c|c|c|c|}
\hline$\#$ & Name & Nucleotide sequence (5'-3') & Source \\
\hline \multirow[t]{2}{*}{1.} & BHE-fwd & GCG GCG ATG TGG TTA TGC TA & \multirow[t]{2}{*}{ Payne et al., 1999} \\
\hline & BHE-rev & CGG CGA GCT GCA TCTCAA TA & \\
\hline \multirow[t]{2}{*}{2.} & B1 & GCT AGG CGA CCC GCA CCA GAT & \multirow[t]{2}{*}{ Huang et al., 2002} \\
\hline & B2 & GGT TAG CGC AAC AAT AGC ATG & \\
\hline \multirow[t]{2}{*}{3.} & Helicase F & TGG CGC ACC(T) GTT(A) TCC(T) CAC CG & \multirow[t]{2}{*}{ Huang et al., 2002} \\
\hline & Helicase R & СCT CA(G)T GGA CCG TA(T)A TCG ACC C & \\
\hline \multirow[t]{4}{*}{4.} & AHEV F-1/SD & TGT TAT T(C)AC ACC CAC CAA G(A)AC GT(C)T G & \multirow[t]{4}{*}{ Sun et al., 2004} \\
\hline & Helic R & ССT CA(G)T GGA CCG TA(T)A TCG ACC C & \\
\hline & AHEV F-2/SD & GCC ACG GCT G(A)TT ACA CCC(T) CAC(T) GT & \\
\hline & Helic R-2 & GAC CCA(G) GGA(G) TTC GAC TGC TT & \\
\hline \multirow[t]{4}{*}{5.} & AHEV ORF2/F-1/SD & TCG CCT(C) GGT AAT(C) ACA(T) AAT GC & \multirow[t]{4}{*}{ Sun et al., 2004} \\
\hline & AHEV ORF2/R-1/SD & GCG TTC(G) CCG(C) ACA GGT(C) CGG CC & \\
\hline & AHEV ORF2/F-2/SD & ACA(T) AAT GCT(C) AGG GTC ACC CG & \\
\hline & AHEV ORF2/R-2/SD & ATG TAC TGA(G) CCA(G) CTG(C) GCC GC & \\
\hline \multirow[t]{4}{*}{6.} & N1 & TTA CCA TTG ACT TTG AAC GGC G & \multirow[t]{4}{*}{ Billam et al., 2005} \\
\hline & N2 & CCG GGC TGA TGG TCT CGA TTA G & \\
\hline & N3 & GCT TGT GCA TTG ACG ATT TCC C & \\
\hline & N4 & CAA TAG GTT ACC CAC GAT GAC G & \\
\hline \multirow[t]{4}{*}{7.} & P1 & ACA ACA TCC ACC СCT ACA AG & \multirow[t]{4}{*}{ Billam et al., 2005} \\
\hline & P2 & ACA GTT TCA ССT CAG GCT CG & \\
\hline & P3 & AGA ACA ATG GTT GGC GGT CC & \\
\hline & P4 & GAG GGC AAG CCA CCT AAA AC & \\
\hline \multirow[t]{2}{*}{8.} & Forw1_C-BLSV & GGT ATG GTT GAT TTT GCC ATA AAG & \multirow[t]{2}{*}{ Bilic et al., 2009} \\
\hline & Rev1_C-BLSV & GCT GCN CGN ARC AGT GTC GA & \\
\hline \multirow[t]{4}{*}{9.} & BLSV-HEVf & AAT GTG CTG CGG GGT GTC AA & \multirow[t]{4}{*}{ Troxler et al., 2011} \\
\hline & BLSV-HEVr & СAT CTG GTA CCG TGC GAG TA & \\
\hline & Probe ORF3-HEV & FAM-CTC CCA AAC GCT CCC AGC CGG A-BHQ1 & \\
\hline & Probe HEV-3 & FAM-CTC CCA AAC GCY CYC AGC CGG A-BHQ1 & \\
\hline \multirow[t]{4}{*}{10.} & F1 & CGT GAC AAC TCA GCC CAG TG & \multirow[t]{4}{*}{ Zhao et al., 2015} \\
\hline & R1 & GCG GTG ACA ACG TCG GTA & \\
\hline & F2 & ATG TAT CTT AGT TGC CAG TTC TGG & \\
\hline & $\mathbf{R 2}$ & СTA CAT CTG GTA CCG TG & \\
\hline
\end{tabular}

from both Australia and Europe. In the United States, primer pairs 2, 3, 4, 5, 6 and 7 were used, and in China, primer pair 10 was used.

\section{References}

1. Agunos A. C., Yoo D., Youssef S. A., Ran D., Binnington B., Hunter D. B.: Avian hepatitis $E$ virus in an outbreak of hepatitis-splenomegaly syndrome and fatty liver haemorrhage syndrome in two flaxseed-fed layer flocks in Ontario. Avian Pathol. 2006, 35, 404-412.

2. Ahmad I., Holla P. R., Jameel S.: Molecular virology of hepatitis E virus. Virus Res. 2011, 161, 47-58.

3. Berke T., Matson D. O.: Reclassification of the Caliciviridae into distinct genera and exclusion of hepatitis E virus from the family on the basis of comparative phylogenetic analysis. Arch. Virol. 2000, 145, 1421-1436.

4. Bilic I., Jaskulska B., Basic A., Morrow C. J., Hess M.: Sequence analysis and comparison of avian hepatitis E viruses from Australia and Europe indicate the existence of different genotypes. J. Gen. Virol. 2009, 90, 863-873.

5. Billam P., Huang F. F., Sun Z. F., Pierson F. W., Duncan R. B., Elvinger F., Guenette D. K., Toth T. E., Meng X. J.: Systematic Pathogenesis and Replication 
of Avian Hepatitis E virus in Specific-Pathogen-Free Adult Chickens. J. Virol. 2005, 79, 3429-3437.

6. Billam P., LeRoith T., Pudupakam R. S., Pierson F. W., Duncan R. B., Meng $X$. $J$.: Comparative pathogenesis in specific-pathogen-free chickens of two strains of avian hepatitis E virus recovered from a chicken with HepatitisSplenomegaly syndrome and from a clinically healthy chicken. Vet. Microbiol. 2009, 139, 253-261.

7. Billam P., Sun Z. F., Meng X. J.: Analysis of the complete sequence of an apparently avirulent strain of avian hepatitis E virus (avian HEV) identified major genetic differences compared with the prototype pathogenic strain of avian HEV. J. Gen. Virol. 2007, 88, 1538-1544.

8. Gerber P. F., Trampel D. W., Opriessing T: Identification and characterization of avian hepatitis E virus in 2013 outbreaks of hepatitis-splenomegaly syndrome in two US layer operations. Avian Pathol. 2014, 43, 357-363.

9. Haqshenas G., Shivaprasad H. L., Woolcock P. R., Read D. H., Meng X. J.: Genetic identification and characterization of a novel virus related to human hepatitis E virus from chickens with hepatitis-splenomegaly syndrome in the United States. J. Gen. Virol. 2001, 82, 2449-2462.

10. Hsu J. W. Y., Tsai H. J.: Avian hepatitis E virus in chickens, Taiwan, 2013 Emerg. Infect. Dis. 2014, 20, 149-151.

11. Huang F. F., Haqshenas G., Shivaprasad H. L., Guenette D. K., Woolcock P. R., Larsen C. T., Pierson F. W., Elvinger F., Toth T. E., Memg X. J.: Heterogeneity and Seroprevalance of a Newly Identified Avian Hepatitis E Virus from Chicken in the United States. J. Clin. Microbiol. 2002, 40, 4197-4202.

12. Huang F. F., Sun Z. F., Emerson S. U., Purcell R. H., Shivaprasad H. L., Pierson F. W., Toth T. E., Meng X. J.: Determination and analysis of the complete genomic sequence of avian hepatitis E virus (avian HEV) and attempts to infect rhesus monkeys with avian HEV. J. Gen. Virol. 2004, 85, 1609-1618.

13. Irza V., Sprygin A.: Hepatitis splenomegay syndrome, a newly identified hen viral disease in Russia. J. Agric. Biol. 2012, 4, 73-77.

14. Johne R., Dremsek P., Reetz J., Heckel G., Hess M., Ulrich R. G.: Hepeviridae: An expanding family of vertebrate viruses. Infect. Genet. Evol. 2014, 27, 212-229

15. Kwon H. M., Sung H. W., Meng X. J.: Serological prevalence, genetic identification, and characterization of the first strains of avian hepatitis $E$ virus from chickens in Korea. Virus Genes 2012, 45, 237-245.

16. Li H., Zhu R., She R., Zhang C., Shi R., Li W., Du F., Wu Q., Hu F., Zhang Y., Soomro M. H., Zheng C.: Case report associated with aspergillosis and hepatitis E virus coinfection in Himalayan griffons. BioMed Res. Int. 2015.

17. Lin J., Norder H., Uhlhorn H., Belak S., Widen F.: Novel hepatitis E like virus in Swedish moose. J. Gen. Virol. 2014, 95, 557-570.

18. Marek A., Bilic I., Prokofieva I., Hess M.: Phylogenetic analysis of avian hepatitis E virus samples from European and Australian chicken flocks supports the existence of a different genus within the Hepeviridae comprising at least three different genotypes. Vet. Microbiol. 2010, 145, 54-61.

19. Meng X. J.: Hepatitis E virus: Animal reservoirs and zoonotic risk. Vet. Microbiol. 2010, 140, 256-265.

20. Meng X. J.: Recent advances in Hepatitis E Virus. J. Viral Hepatitis 2010, 17, $153-161$.

21. Meng X. J., Anderson D. A., Arankalle V. A., Emerson S. U., Harrison T. J., Jameel S., Okamoto H.: Create two new genera, Orthohepevirus and Avihepevirus, and remove the current sole genus Hepevirus in the family Hepeviridae. Taxonomic proposal to the ICTV Executive Committee 2010.

22. Payne C. J., Ellis T. M., Plant S. L., Gregory A. R., Wilcox G. E.: Sequence data suggesting big liver and spleen disease virus (BLSV) is genetically related to hepatitis E virus. Vet. Microbiol. 1999, 68, 119-125.

23. Peralta B., Biarnes M., Ordonez G., Porta R., Martin M., Mateu E., Pina S., Meng X. J.: Evidence of widespread infection of avian hepatitis E virus (avian HEV) in chicken from Spain. Vet. Microbiol. 2009, 137, 31-36.

24. Reuter G., Boros A., Matics R., Kapusinszky B., Delwart E., Pankovics P.: A novel avian-like hepatitis $E$ virus in wild aquatic bird, little egret (Egretta garzetta), in Hungary. Infection, Genetics \& Evolution 2016, 46, 74-77.

25. Reuter G., Boros A., Matics R., Kapusinszky B., Delwart E., Pankovics P.: Divergent hepatitis E virus in birds of prey, common kestrel (Falco tinnunculus) and red-footed falcon (F. vespertinus), Hungary. Infection, Genetics \& Evolution 2016, 43, 343-346

26. Smith D. B., Simmonds P., Jameel S., Emerson S. U., Harrison T. J., Meng X. J., Okamoto H., Van der Poel W. H. M., Purdy M. A.: Consensus proposals for classification of the family Hepeviridae. J. Gen. Virol. 2014, 95, 2223-2232.

27. Sprygin A. V., Nikonova Z. B., Zinyakov N. G.: Avian hepatitis E virus identified in Russian chicken flocks exhibits high genetic divergence based on the ORF2 capsid gene. Avian Pathol. 2012, 41, 459-463.

28. Sun Z. F., Larsen C. T., Dunlop A., Huang F. F., Pierson F. W., Toth T. E., Meng $X$. $J$ : : Genetic identification of avian hepatitis E virus (HEV) from healthy chicken flocks and characterization of the capsid gene of 14 avian HEV isolates from chickens with hepatitis - splenomegaly syndrome in differen geographical regions of the Unites States. J. Gen. Virol. 2004, 85, 693-700.
29.Sun Z. F., Larsen C. T., Huang F. F., Billam P., Pierson F. W., Toth T. E., Meng $X . J$. : Generation and infectivity titration of an infectious stock of avian hepatitis $E$ virus (HEV) in chickens an cross-species infection of turkeys with avian HEV. J. Clin. Microbiol. 2004, 42, 2658-2662.

30. Syed S. F., Sun Y., Du T., Chen Y., Liu B., Wang X., Li H., Nan Y., Zhou E-M., Zhao $Q$.: Evaluation of recombinant Chinese avian hepatitis E virus (CaHEV) ORF2 and ORF3 proteins for protection of chickens against CaHEV infection. Vaccine 2017, 35, 3482-3489.

31. Szeleszczuk P., Żbikowski A., Dolka I., GawlikP., Szewczyk R., Mieszczyński T.: Zakażenia wirusem zapalenia wątroby typu E u drobiu. Mat. I Kongresu Praktyki Weterynaryjnej. Łódź 2011, 153-156.

32. Troxler S., Marek A., Prokofieva I., Bilic I., Hess M.: TaqMan Real-Time Reverse Transcription-PCR Assay for Universal Detection and Quantification of Avian Hepatitis E Virus from Clinical Samples in the Presence of a Heterologous Internal Control RNA. J. Clin. Microbiol. 2011, 49, 1339-1346.

33. Troxler S., Pać K., Prokofieva I., Liebhart D., Chodakowska B., Furmanek D. Hess M.: Subclinical circulation of avian hepatitis E virus within a multiple-age rearing and broiler breeder farm indicates persistence and vertical transmission of the virus. Avian Pathol. 2014, 43, 310-318.

34. Vasickova P., Psikal I., KralikP., Widen., Hubalek., Pavlik I.: Hepatitis E virus: a review. Vet. Med. (Praha) 2007, 52, 365-384.

35. Woo P. C. Y., Lau S. K. P., Teng J. L. L., Tsang A. K. L., Joseph M., Wong E. Y. M., Tang Y., Sivakumar S., Xie J., Bai R., Wernery R., Wernery U., Yuen $K$. $Y$ : New hepatitis E virus genotype in camels, the Middle East. Emerg. Infect. Dis. 2014, 20, 1044-1048.

36. World Health Organization: Hepatitis E vaccine: WHO position paper, May 2015. Weekly Epidemiol. Rec. 2015, 90, 185-200.

37. Zhang X., Bilic I., Troxler S., Hess M.: Evidence of genotypes 1 and 3 of avian hepatitis E virus in wild birds. Virus Res. 2017, 228, 75-78.

38. Zhao Q., Liu B., Sun Y., Du T., Chen Y., Wang X., Li H., Nan Y., Zhang G., Zhou E. M.: Decreased egg production in laying hens associated with infection with genotype 3 avian hepatitis E virus strain from China. Vet. Microbiol. 2017, 203, 174-180.

39. Zhao Q., Xie S., Sun Y., Chen Y., Gao J., Li H., Wang X., Syed S. F., Liu B., Wang L., Zhang G., Zhou E. M.: Development and evaluation of a SYBR Green real-time RT-PCR assay for detection of avian hepatitis E virus. BMC Veterinary Research 2015, 11:195. Doi:10.1186/s12917-015-0507-5

40. Zhao Q., Zhou E. M., Dong S. W., Qiu H. K., Zhang L., Hu S. B., Zhao F. F., Jiang S. J., Sun Y. N.: Analysis of Avian Hepatitis E Virus from Chickens, China. Emerg. Infect. Dis. 2010, 16, 1469-1472.

Corresponding author: Joanna Nerc, DVM, Nowoursynowska 159C, 02-776 Warsaw, Poland; e-mail: joanna_nerc@sggw.pl 